\title{
Desain Interior Restoran dan Pusat Oleh-Oleh dengan Konsep Inovatif Bernuansa Familiarity
}

\author{
Karima Oktabrilianza dan Aria Weny Anggraita \\ Departemen Desain Interior, Fakultas Teknik Sipil dan Perencanaan, Institut Teknologi Sepuluh Nopember (ITS) \\ e-mail: ariaweny@interior.its.ac.id
}

\begin{abstract}
Abstrak-Persaingan bisnis restoran di Surabaya yang semakin ketat, menuntut sebuah restoran untuk meningkatkan daya saing. Untuk meningkatkan daya saing, sebuah restoran harus mampu memberikan daya tarik bagi pengunjung dan dapat meningkatkan kepuasan pengunjungnya. Dimana hal tersebut dapat dicapai dengan perencanaan desain interior restoran yang tepat. "Bu Rudy" adalah salah satu restoran dan pusat oleh-oleh dengan keunggulan kompetitif brupa keramahan dan keakraban yang memiliki daya tarik tinggi di Surabaya. Restoran ini selalu padat oleh pengunjung yang mayoritas adalah keluarga atau teman. Kondisi tersebut apabila dibiarkan dapat menurunkan tingkat kepuasan pengunjung restoran dalam jangka panjang. Suasana interior restoran dan sarana prasarana restoran "Masakan Khas Bu Rudy" saat ini perlu adanya penyesuaian agar dapat meningkatkan daya tarik pengunjung. Dengan perancangan desain interior restoran "Masakan Khas Bu Rudy" diharapkan mampu meningkatkan kepuasan dan daya tarik pengunjung yaitu dengan menganalisa tentang kenyamanan dan pelayanan restoran secara optimal, menampilkan desain interior sesuai corporate image secara inovatif dan menampilkan suasana interior yang ramah dan akrab dengan pemilihan bentuk, warna, pencahayaan dan penataan layout.
\end{abstract}

Kata Kunci-Interior Restoran, Inovatif, Keakraban.

\section{PENDAHULUAN}

$\mathrm{R}$ ESTAURAN di Surabaya tumbuh hingga 20\% setiap tahunnya menurut Ketua Asosiasi Pengusaha Kafe dan Restoran Indonesia (Apkrindo) Jatim Tjahjono Haryono, Kepala DPPK Kota Surabaya, Yusron Sumartonoini mengungkapkan, pada tahun 2016 jumlah restoran yang beroperasi di Surabaya dan sudah masuk sebagai wajib pajak sebanyak 1.712. Pertumbuhan restoran ini dipicu makin tingginya daya beli masyarakat. Hal tersebut menunjukkan persaingan bisnis restoran yang semakin ketat.

Menurut Soekresno (2000:16) Restoran merupakan usaha komersial yang melayani jasa makanan maupun minuman untuk umum yang dikelola secara professional. Tujuan dari oprasional restoran adalah untuk mencari keuntungan dan memberikan layanan yang terbaik bagi pengunjung. Restoran dituntut untuk memberikan cita rasa, pelayanan dan kenyamanan kepada pengunjung. Untuk meningkatkan daya saing, sebuah restoran harus mampu memberikan daya tarik bagi pengunjung dan dapat meningkatkan kepuasan pengunjungnya. Dimana hal tersebut dapat dicapai dengan perencanaan desain interior restoran yang tepat.

Dinas Kebudayaan dan Pariwisata Kota Surabaya pada tahun 2012 mencatat grafik jumlah restoran berdasarkan jenis makanan, restoran dengan makanan khas Indonesia merupakan makanan yang paling diminati kedua setelah menu makanan café. Salah satu restoran yang terkenal dengan menu makanan khas Indonesia di Surabaya adalah "Masakan Khas
$\mathrm{Bu}$ Rudy”. Restoran sekaligus tempat oleh-oleh ini menyajikan menu masakan daerah yang populer dengan nasi udang dan sambelnya yang pedas.

Dilansir dari ulasan TripAdvisor, restoran "Masakan Khas Bu Rudy" mendapatkan peringkat ke 7 dari 1280 restoran di Surabaya karena banyak memperoleh ulasan positif dari pengunjungnya. Hal tersebut menunjukan bahwa "Masakan Khas Bu Rudy" memiliki daya tarik yang tinggi yang dipadati pengunjung, kondisi restoran tersebut mengakibatkan sesak dan panas saat berada di dalam restoran. Dimana hal tersebut dapat menurunkan tingkat kepuasan pengunjung restoran. Disamping itu kondisi interior restoran dan sarana prasarana restoran "Masakan Khas Bu Rudy" saat ini terlihat kurang menarik dan perlu adanya penyesuaian. Dalam jangka panjang hal tersebut dapat menurunkan daya tarik pengunjung.

Selaku pemilik restoran ingin usaha restoran yang telah dirintisnya sejak tahun 2000 ini terus berkembang. Salah satu wujudnya adalah dengan membuka cabang restoran baru. Sebagai bentuk apresiasi atas usaha yang telah dirintis, pemilik restoran cabang menginginkan untuk mengangkat kembali perjuangan awal usaha membuka restoran yang hingga kini telah dikenal banyak orang. Keramahan dan keakraban kepada pengunjung telah menjadi keunggulan kompetitif restoran yang akan dihadirkan pada suasana di restoran cabang. Disamping itu, mayoritas pengunjung restoran adalah keluarga dan teman yang memiliki interaksi dekat dan akrab. Untuk kedua hal tersebut diperlukan interior dengan suasana yang dapat mendukung suasana keakraban.

Untuk meningkatkan daya saing pada perencanaan desain kedepannya akan dianalisa mengenai kenyamanan dan pelayanan restoran, corporate image restoran serta sejarah tentang perjuangan Bu Rudy dan konsep familiarity. Dengan perancangan desain interior restoran cabang "Masakan Khas Bu Rudy" diharapkan mampu meningkatkan kepuasan dan daya tarik pengunjung yaitu dengan memberikan kenyamanan dan pelayanan restoran secara optimal, menampilkan desain interior sesuai corporate image dan sejarah restoran "Masakan Khas Bu Rudy" secara inovatif dan menampilkan suasana interior familiarity dengan pemilihan bentuk, warna, pencahayaan dan penataan layout.

\section{URAIAN PENELITIAN}

\section{A. Metode Pengumpulan Data}

- Data primer merupakan sejumlah data yang didapat langsung dari lapangan melalui pihak-pihak yang berkaitan langsung dengan objek tersebut. Data tersebut didapat dari observasi atau pengamatan langsung dan wawancara. 
- Data sekunder merupakan sejumlah data yang diperoleh secara tidak langsung dari lapangan maupun pihak yang berkaitan langsung dengan objek melainkan melalui studi pustaka, majalah, internet dan media lainnya.

\section{B. Metode Analisa Data}

- Observasi atau survey lapangan dilakukan untuk mengetahui kondisi mengenai restoran "masakan khas bu rudy" yang sebenarnya, sehingga dapat memperoleh gambaran tentang eksisting, serta menganalisa desain interiornya

- Wawancara dilakukan dengan responden yaitu Owner/ pemilik dari restoran "Masakan Khas Bu Rudy". Wawancara dilakukan untuk mengetahui kebutuhan dan keinginan serta masalah dari sudut pandang pemilik restoran sendiri.

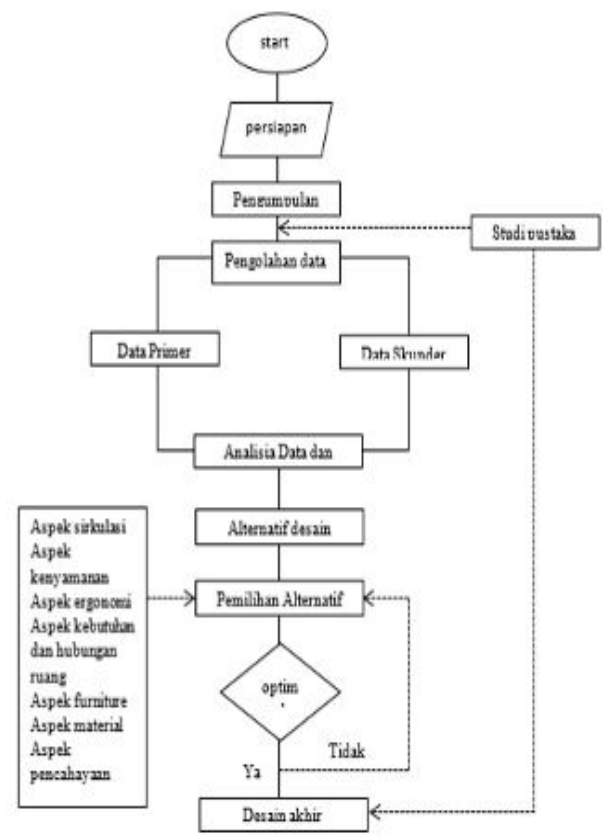

Gambar 1. Diagram desain

\section{KONSEP DESAIN}

\section{A. Konsep Desain}

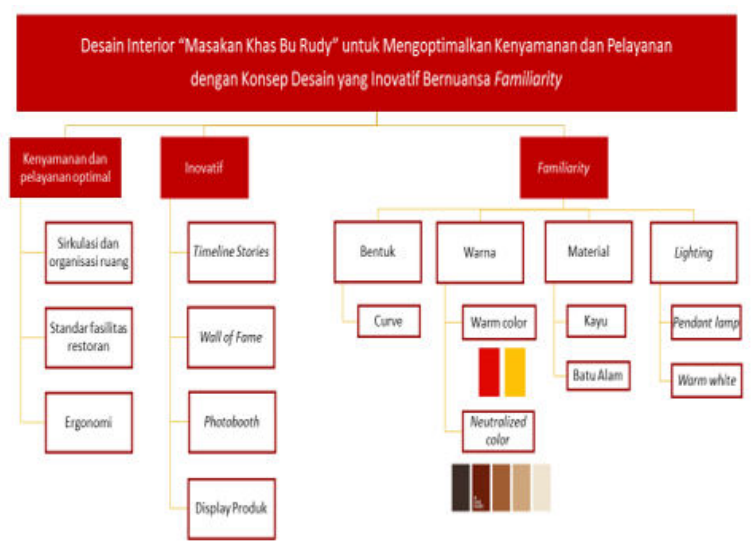

Gambar 2. Tema Desain.
Konsep desain merupakan hasil pertimbangan dari analisa riset. Konsep desain yang akan gunakan untuk Restoran Cabang. Untuk dapat mengoptimalkan pelayanan dan kenyamanan diperlukan penataan interior agar dapat membentuk sirkulasi dan pengorganisasian ruang, penyesuaian fasilitas dan ergonomi. Untuk menghadirkan konsep inovatif di dalam restoran cabang baru adalah dengan memberikan timeline stories, wall of fame, photobooth dan display produk. Konsep familiarity dihadirkan karena permintaan pemilik dan melihat pengunjung restoran yang mayoritas adalah keluarga dan teman sehingga membutuhkan suasana yang akrab dengan penataan interior melalui pemilihan warna, bentuk, material dan lighting.

\section{B. Konsep Mikro}

Konsep desain mikro memberi sedikit gambaran tentang konsep desain yang akan digunakan dalam perancangan desain interior restoran. Berikut merupakan penjabaran konsep mikro yang diaplikasikan dalam restoran Masakan Khas Bu Rudy Cabang Surabaya Barat.

1) Konsep Warna

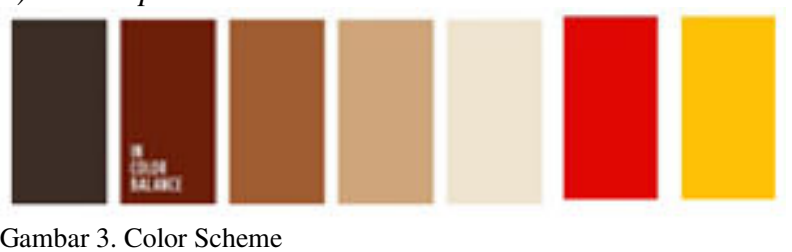

Pada kategori warna merah, jingga, oranye, dan kuning. Pada umumnya warna tersebut memiliki kecenderungan yang menyenangkan, bersemangat, ketegasan, kegembiraan, nyaman, dan dapat merangsang. Warna-warna diantara kelompok warm color dan cool color seperti begie, brown, taupe, cream, ivory, off black dan off white disebut warna penetral. Warna penetral pada umumnya penting untuk setiap perencanaan warna. Warna tersebut menunjukan ketentraman, hening, hidup, kalem dan pendukung

Pada hasil studi warna, kelompok warm color seperti merah dan kuning akan diaplikasikan sebagai stimulus untuk merangsang suasana hangat dan menyenangkan dan warna tersebut juga merupakan warna dari corporate image restoran. Sebagai penetral yang dapat menimbulkan suasana hangat akan digunakan warna-warna seperti coklat, begie, dan cream. 2) Konsep Bentuk
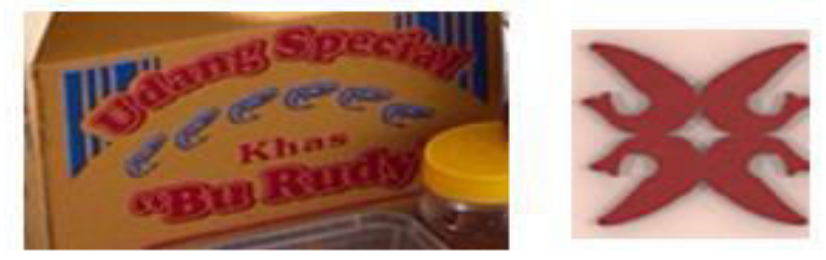

Gambar 4. Konsep Bentuk.

Bentuk lengkung merupakan bentuk konstan, menyatukan, dan menyenangkan. Jika digunakan dalam interior, bentuk lengkung dapat memberikan efek dramatis. Untuk mendukung konsep familiarity diperlukan bentuk yang dapat memberikan efek yang menyenangkan yang akan diaplikasikan pada konsep bentuk perancangan selanjutnya yaitu dominasi bentuk lengkung. (Beginning of Interior Environments). Bentuk 
lengkung didapatkan dari bentuk udang yang merupakan salah satu produk unggulan restoran yang digunakan menjadi motif elemen estetis.

\section{3) Konsep Lantai}

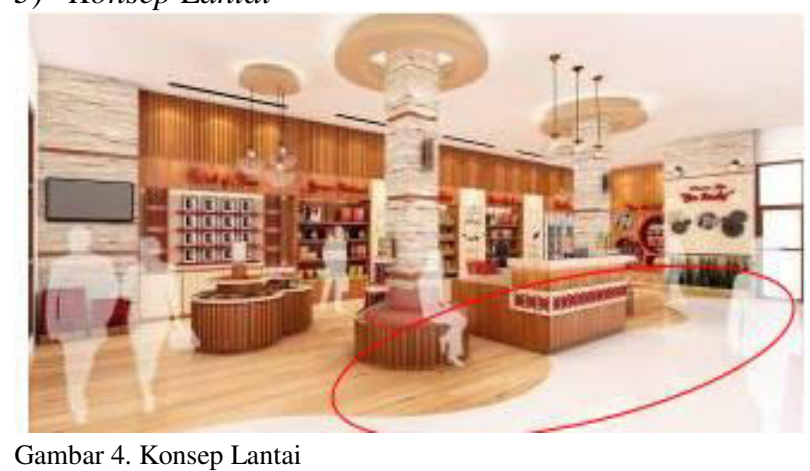

Aplikasi lantai pada area oleh-oleh dan area restoran dibedakan. Perbedaan untuk memberi batas antara kedua area tersebut agar mempermudah membentuk sirkulasi pengunjung. Perbedaan berupa material dan warna pada lantai. Di area restoran material yang digunakan adalah keramik, karena mudah dalam perawatan dan lebih tahan lama. Warna yang digunakan adalah dominan warna coklat karena dapat memberikan suasana hangat pada ruangan. Motif keramik yang digunakan adalah motif polos dan keramik motif dan keramik motif kayu.

4) Konsep Dinding

Dinding pada restoran dimanfaatkan sebagai media menyampaikan cerita tentang secara informatif berupa timeline stories, wall of fame, photobooth, dan marquee.

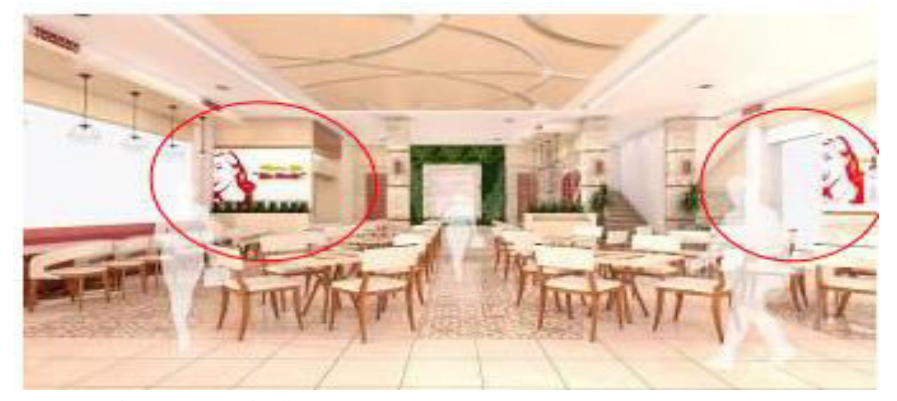

Gambar 5. Konsep Dinding

\section{5) Konsep Plafon}

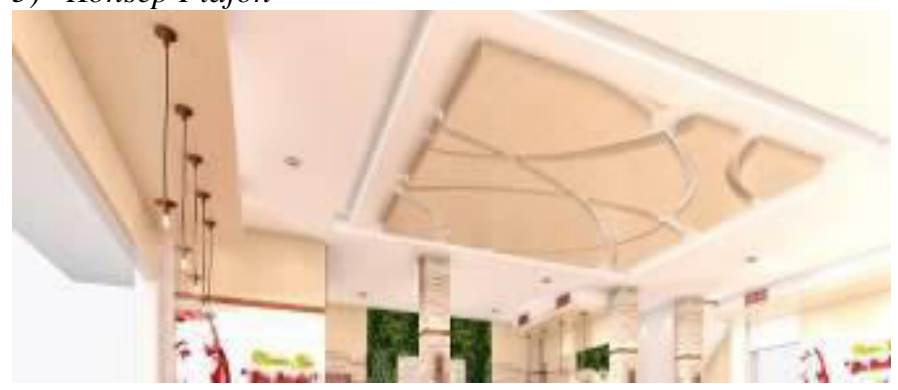

Gambar 6. Konsep Plafon

Pada konsep plafon pada restoran menggunakan down ceiling dengan material gypsum dan diaplikasikan hidden lamp berwarna kuning untuk menambah suasana hangat. Elemen estetis yang digunakan adalah lampu pendant lamp yang dipasang pada atas meja makan untuk memberikan kesan dekat dan akrab. Pada beberapa area akan digunakan plafon dengan papan GRC board motif kayu untuk menambah suasana hangat

\section{6) Konsep furniture}

Konsep bentuk furniture yang digunakan merupakan bentuk curved atau melingkar dimana bentuk-bentuk tersebut dapat menyebabkan suansana yang lebih menyenangkan. Warna yang digunakan adalah warna dominan coklat kayu. Warna merah dan kuning dapat digunakan pada cushion kursi. Pada area outdoor, furniture yang digunakan merupakan material yang tahan terhadap cuaca. Meja dan kursi makan menggunakan bahan rotan sintetis atau menggunakan kayu.

\section{7) Konsep Elemen Estetis}
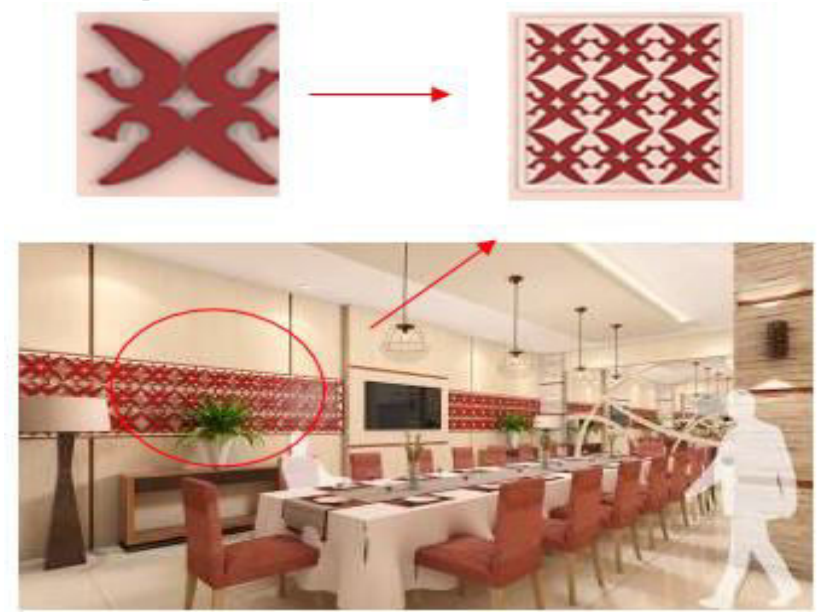

Gambar 7. Konsep Elemen Estetis

Penggunaan stilasi bentuk udang yang merupakan produk utama masakan khas Bu Rudy dapat digunakan sebagai partisi dan elemen estetis pada dinding dengan menggunakan teknik metal cutting laser. Bentuk karakter udang ini juga diaplikasikan untuk lampu gantung.

\section{DESAIN AKHIR}

\section{A. Area Terpilih 1: Area Oleh-Oleh}

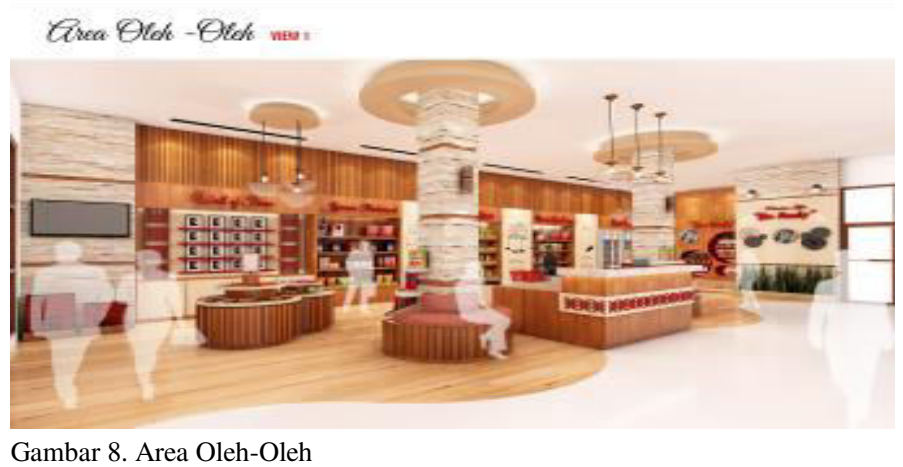

Gambar diatas adalah view ketika pertamakali masuk ke area oleh-oleh, terdapat wall of fame yang menjadi point of interest. Selanjutnya terdapat rak display yang terdapat cerita tentang sambal $\mathrm{Bu}$ Rudy yang disusun berurutan yang bertujuan untuk mengarahkan pandangan pengunjung yang berisi cerita tentang sambal bu rudy. 


\section{B. Area Terpilih 2: Area Makan}

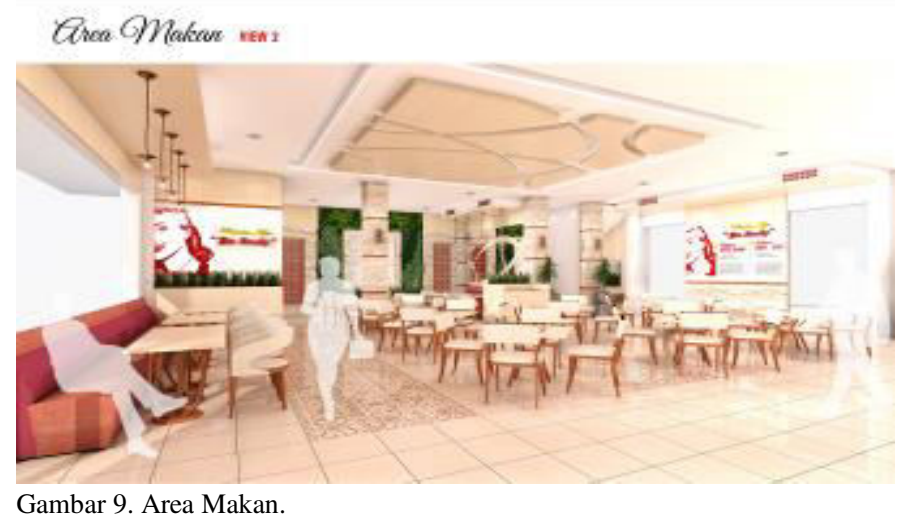

Gambar diatas merupakan view area makan utama. Pattern lantai dibedakan untuk membentuk alur sirkulasi pengunjung. warna yang digunakan merupakan warna merah dan coklat yang merupakan warna dari konsep familiarity yang dapat memberikan kesan hangat. Kehangatan juga didapatkan dari warna lampu warm white serta penggunnaan pendant lamp pada beberapa area. Konsep inovatif yang berisi timeline stories dan wall of fame diterapkan pada dinding area makan utama dengan pengecatan dan penggunaan sticker.

\section{Area Terpilih 3: Ruang Makan VIP}

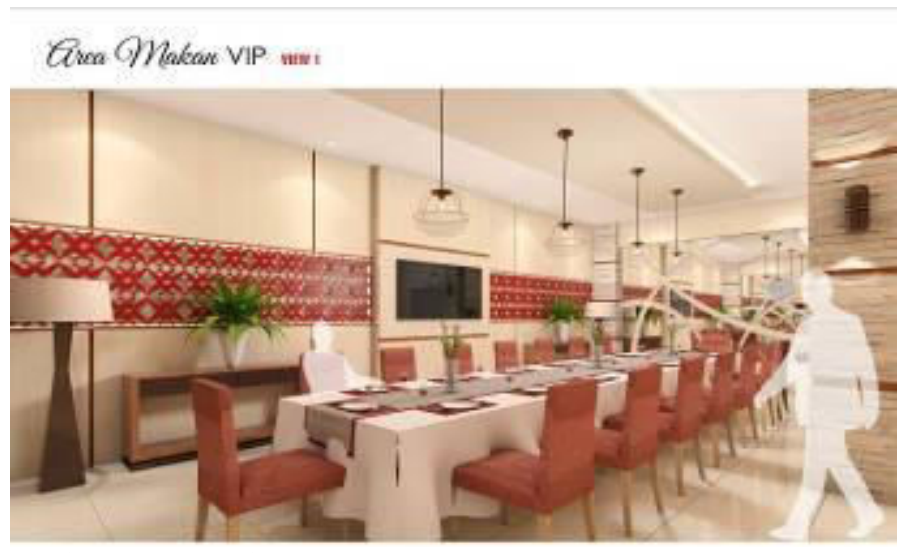

Gambar 10. Area Makan VIP

Area VIP merupakan area yang digunakan untuk pertemuan yang lebih privat. Di ruang VIP didesain lebih ekskulif dengan penggunaan kursi upholstery namun dengan bentuk yang sederhana dan material kayu mahoni agar tetap ringan untuk moveable. Partisi dengan motif udang dalam ruangan yang berfungsi sebagai elemen estetis yang menunjukkan ciri khas restoran.

\section{KESIMPULAN}

\section{A. Kesimpulan}

Dari pembahasan Desain Interior Restoran "Masakan Bu Rudy" dengan konsep inovatif bernuansa familiarity dapat disimpulkan beberapa hal, antara lain:
1. Pengorganisasian ruang dan membentuk alur sirkulasi sesuai dengan kebutuhan pengguna dapat memaksimalkan operasional restoran sehingga dapat meningkatkan pelayanan restoran yang berdampak pada kenyamanan pengguna.

2. Untuk meningkatkan daya tarik penggunjung diperlukan desain yang dapat mempresentasikan corporate image yang dikemas secara inovatif dengan memberikan informasi berupa cerita sejarah restoran di timeline stories, wall of fame untuk menunjukan keeksistenisan restoran, menambahkan fasilitas berfoto berupa photobooth dan visual merchendaising pada area oleholeh. Desain inovatif juga diterapkan pada pemilihan fiurniture dan elemen estetis yang disesuaikan dengan kebutuhan pengguna untuk meningkatkan operasional restora.

3. Konsep kebersamaan dapat diperoleh dengan tata letak layout, pencahayaan, materia; dan warna.

B. Saran

1. Untuk menentukan konsep desain harus mempertimbangkan fungsi, aktivitas dan kebutuhan pengguna agar dapat menyelesaikan masalah untuk menciptakan ruangan yang ideal.

2. Dalam merancang desain interior restoran sebaiknya dapat memberikan ciri khas restoran yang digunakan sebagai identitas utama sehingga dapat selalu diingat oleh pengunjung.

\section{DAFTAR PUSTAKA}

[1] Menurut Keputusan Menteri Pariwisata, Pos dan Telekomunikasi No.KN.73/PVVI05/MPPT-85 tentang Peraturan usaha Rumah Makan

[2] peraturan Menteri Kesehatan RI No. 304/Menkes/Per/89 tentang persyaratan rumah makan)

[3] Sugiarto, dan Sri Sulartiningrum, 2001. Pengantar akomodasi dan Restoran. Jakarta. PT. Gramedia Pustaka Utama.Sulartiningrum (2003 : 91-96)/

[4] Marsum, WA. 1993. Restoran dan Segala Permasalahanya.Yogyakarta: Andi Offset

[5] Atmodjo, Marsum Widjojo.(2007).Restoran dan segala Permasalahannya.Yogyakarta:Andi

[6] Suptandar, J. Pamudji. 1999. Disain Interior: Pengantar Merencana Interior untuk Mahasiswa Disain dan Arsitektur. Penerbit Djambatan : Jakarta

[7] Ching, Francis D.K. 2000. Arsitektur: Bentuk, Ruang dan Tatanan. Jakarta: Penerbit Erlangga.

[8] Neufert, Ernst. Terjemahan oleh Dr. Ing Sunarto Tjahjadi, jilid 1, Data Arsitek. Jakarta. Erlangga

[9] Phyllis Sloan Allen. Miriam F. Stimpson. Lynn M. Jones. 2000. Beginnings Of Interior Environments $8^{\text {th }}$ edition

[10] Angeli Kosasih, Laksmi Kusuma Wardani, Lucky Basuki. JURNAL INTRA Vol. 2, No. 2, (2014) 132-139. Perancangan Interior Griya Lanjut Usia St.Yosef di Jawa Tengah Dengan Konsep Keakraban.

[11] Nugroho, Eko. 2008. Pengenalan Teori Warna. Yogyakarta:Andi Offset

[12] Colour Scheme Sourcebook

[13] Tata Cahaya Interior 